\title{
Effects of Partial RCCI Application of LPG on Performance, Combustion and Exhaust Emissions in a Diesel Engine Powered Generator
}

\author{
Ahmet Aydin ${ }^{1 *} \mathbb{D}$, Hüseyin Aydin² ${ }^{\mathbb{D}}$ \\ ${ }^{1 *}$ Batman University, Mechanical Engineering Department, Batman, Turkey. (e-mail: g.ahmetaydinn@ gmail.com). \\ ${ }^{2}$ Batman University, Mechanical Engineering Department, Batman, Turkey. (e-mail: husayyinaydin@ gmail.com).
}

\section{ARTICLE INFO}

Received: Nov., 18. 2019

Revised: Sep., 10. 2020

Accepted: Feb, 01. 2021

Keywords:

Diesel engine

Dual-Fuel system

Emission

LPG

Performance

Corresponding author: Ahmet Aydin

ISSN: 2536-5010 | e-ISSN: 2536-5134

DOI: https://doi.org/10.36222/ejt.647912

\section{ABSTRACT}

In this study, engine performance, combustion and emissions of a diesel engine used for driving an electrical generator was investigated with LPG fumigation into the manifold of the engine as secondary fuel. Tests were carried out in 4 cylinders, 4 strokes water-cooled and direct-injection diesel engine generator. According to the test results; cylinder pressure, average gas temperature and peak values of heat release rate were increased as amount of LPG was increased. However, brake specific fuel consumption and mass fuel consumption were higher as well. Generally, with LPG addition, CO and HC emissions were found higher. Up to $40 \%$ LPG addition, $\mathrm{CO}_{2}$ emissions were lowered and over $40 \%$ LPG addition, $\mathrm{CO}_{2}$ emission increased. With increasing LPG ratio, there was a decrease in NOx emission values. On the other hand, generally, as LPG content was increased, $\mathrm{O}_{2}$ emissions were decreased significantly. Generally, the LPG usage of certain levels were found to be possible as secondary fuel in diesel engines. However, its usage in the engine up to certain levels resulted in considerable negative changes in performance, combustion and emissions changes. Over 55\% LPG fumigation resulted in quite high flame velocity and propagation which eventually resulted in the accelerated cylinder pressure for per crank angle. This condition may be accepted as the starting of the knock. Therefore, only certain low amounts of LPG usage as secondary nonreactive fuel in diesel engine were found to be possible.

\section{INTRODUCTION}

Petroleum supplies most of the energy needs so as to be used as fuel in the world. As a result of extreme use of petroleum, the oil reserves are reducing. Due to gradual increase in reserve usage and exhaust emissions, it is forced humanity to face with air pollution and the scarce of the existing energy resources. Therefore an attempt has been made to discover the alternative fuels $[1,2]$. Besides, the extreme usage of fuels in the world lead to considerable levels of smoke and particulate emissions to the atmosphere. Also, the increased number of diesel engines has led to alternative fuel searches.

Liquefied Petroleum Gas (LPG), which significantly reduces emissions in internal combustion (IC) engines, may also be used in diesel engines. LPG cannot be used alone in diesel engines because it has a low reactivity fuel and has a low cetane number and will need a combustion start. In diesel engines, LPG can be used with auxiliary methods to ignite. These methods include cetane number enhancer additives, LPG can be used together with pilot injections of high reactivity fuel with high cetane number such as diesel fuel [3].
Low-cost production, storage, easy to obtain, and low exhaust emissions of LPG make it possible to use as an alternative fuel for internal combustion engines [4].

In the literature, some studies related LPG usage in diesel engines as follows;

Kannan et al. [5] This study investigated the performance of LPG fueled Homogeneous charge compression ignition (HCCI) of inlet air preheating at different loads. Experiments were carried out using LPG as the primary fuel with a single cylinder $1500 \mathrm{rpm}$ constant engine speed. According to the results; HC emissions at full load were higher in LPG fuel compared to diesel fuel. CO emissions for LPG were higher when compared to diesel. Especially under low load and no load conditions. Less NOx emissions were observed in LPG compared to diesel fuel. When compare to pure diesel, the brake thermal efficiency of LPG was found lower at all loads. A decrease of approximately was $20 \%$ detected in the exhaust gas temperature in all combustion modes compared to diesel. Although peak pressures were better in LPG compared to diesel fuel. It was observed that the peak cylinder pressure decreased. Anye Ngang and Ngayihi Abbe [6] In this study the performance and emission characteristics of a dual fuel 
(diesel-LPG) engine were investigated by changing the LPG mass fraction. The four-cylinder engine was tested at different loads and at different speeds. It was observed that the maximum in-cylinder pressure increased with the increase in engine speed. In addition, with the increase in the LPG mass fraction the cylinder pressure and temperature increased as well as the fuel consumption. It has been observed, when the LPG mass ratio is increased from $50 \%$ to $60 \%$ that there is a decrease in $\mathrm{HC}$ and NOx emissions and an improvement in engine performance (torque, efficiency, power). Vinoth et al. [7] In this study were the use of diethyl ether (DEE) as an ignition enhancer and LPG as a primary fuel in a direct injection single-cylinder, water-cooled and four-stroke diesel engine investigated. They found that knocking decreased with the addition of diethyl ether. In addition, it was observed that $\mathrm{CO}$ and NOx emissions decreased with a higher percentage of Diethyl ether compared to LPG. Brake thermal efficiency increased in the range of $2 \%$ to $10 \%$ at all loads for all LPG rate of flow, while the brake thermal efficiency decreased by approximately $5 \%$ with the addition of diethyl ether. The best performance, the highest efficiency and the least noisy situation were observed with the addition of $15 \%$ DEE and LPG flow rate of $0.221 \mathrm{~kg} / \mathrm{h}$. Guan et al. [8] In this study, pilot waste cooking oil biodiesel (WCOB) or pilot diesel and fumigated LPG were carried out with a 4-cylinder diesel engine operated at three different loads. With the addition of LPG, LPG is expressed as a percentage of power expression (LPSP), which varies between $10 \%$ and $30 \%$ at each load. According to the results; They found a slight decrease in peak heat release rate (HRR) and peak in-cylinder pressure in dual fuel compared to single fuel operation at low load. The effect of LPSP on brake thermal efficiency and brake specific fuel consumption improved at high load for both pilot fuel types, but worse at low load. They found that LPG-WCOB was better at reducing particulate emissions, while LPG diesel operation was better at reducing NOx emissions. Rimkus et al. [9] In this study was the effect of LPG on environmental, energy performance and combustion in a compression ignition (CI) engine working on a diesel fuel investigated. By adding LPG to diesel fuel are reduced $\mathrm{CO} 2$ emissions. There was a decrease in NOx emission observed, while $\mathrm{CO}$ and $\mathrm{HC}$ emissions increased with LPG additive. Irgin et al. [10] In this study were the effects of dual fuel (diesel/LPG) on emissions and engine performance investigated. According to the test results; There was a slight increase in NOx emission compared to diesel fuel, while a decrease in $\mathrm{HC}$ and $\mathrm{CO}$ emissions was detected. It also observed improvement in effective efficiency and specific fuel consumption. Nugroho et al. [11] In this study was dual fuel used in C223 diesel engine as LPG as secondary fuel. The experiments were carried out at different engine speeds and different LPG concentrations $(35 \%, 45 \%$ and $75 \%)$. According to the results; They observed that brake specific fuel consumption, brake thermal efficiency and power were better in dual fuel compared to single fuel. Improvements were seen in brake thermal efficiency (BTE) with 45\% LPG. Ünal et al. [12] In this study were cost and energy analyzes carried out according to the results obtained with different drying air inlet temperatures for heating the drying air in the drying chamber of the LPG-fueled horizontal type corn drying plant. According to the results; It has been observed that when the drying inlet air temperature is increased, fuel consumption, unit drying cost increase and energy efficiency decreases. They observed that while the relative humidity of the heater inlet air increased, the energy efficiency decreased, while the unit drying cost and fuel consumption increased. Aliustaoğlu and Ayhan [13] They investigated in this study the effects of diesel-LPG fuel mixture on emissions and performance in a single-cylinder direct injection diesel engine. According to the test results; It has been observed that the $20 \%$ LPG- $80 \%$ diesel fuel mixture provides superiority in terms of specific fuel consumption and cost without causing any negative effects on performance. It has been observed in addition, that they provide very important improvements in emissions. Sendilvelan and Sundarraj [14] In this study was LPG used as a secondary fuel in a direct-injection, single-cylinder, fourstroke, water-cooled and constant speed (1500 rpm) diesel engine under all loading conditions. According to the test results; Brake thermal efficiency slightly decreased due to the use of LPG. Significant reduction in diesel fuel consumption was observed. A slight increase was observed in $\mathrm{CO}$ and $\mathrm{HC}$ emissions at low loads, while a decrease was observed with increasing load. With the use of LPG was a reasonable reduction in smoke density and NOx emissions observed. Aktaş and Doğan [15] made an investigation on the effect of diesel and LPG fuels on emission and performance in a direct injection single cylinder diesel engine was investigated. Brake specific fuel consumption was increased for the fuel mixture including LPG above $40 \%$. It has been observed that NOx emissions were decreased and $\mathrm{CO}$ and $\mathrm{HC}$ emissions were increased. Another research on diesel engine with a singlecylinder air-cooled direct injection was made by Yiğit [16]. According to his results, the use of LPG at 25\% and 20\% load was increased engine power and torque. $\mathrm{CO}$ emissions have been increased by a certain amount and then tended to decrease. As the amount of LPG increased, the increase in smoke emissions was observed. In addition, an increase in NOx and HC emissions has been observed. Different LPG ratios with different butane/propane ratios were used in the dual fuel diesel engine by Saleh [17]. According to the test results as the propane ratio increased and the $\mathrm{CO}$ emissions decreased but the NOx emission decreased as the butane ratio increased. The best results in terms of performance and emissions are ensured when using 40\% LPG and 60\% diesel fuel with $70 \%$ propane and $30 \%$ butane ratio. Another work was carried out on the experiments on a four-cylinder, fourstroke, water-cooled engine by Aydın and Acaroğlu [18]. The tests were firstly made with gasoline, followed by LPG. The engine emissions and performance values were compared. The results of the tests showed that LPG does not led decrease in performance with respect to gasoline fuel. Abd Alla et al. [19] converted the single-cylinder Ricardo E6 compression ignition engine into a dual-fuel engine with pilot injection. They used methane and propane fuels as the secondary fuel. As the amount of the pilot injection was increased while $\mathrm{CO}$, NOx and HC emissions were decreased, thermal efficiency was increased. Çarman et al. [20] studied in a diesel engine using $70 \%$ diesel fuel with $30 \%$ LPG and pure diesel fuel to examine for the emissions and performance characteristics. Test results were showed an increase of $5.8 \%$ in engine power and torque during dual fuel operation, a decrease in smoke emissions and a decrease in NOx of $5.9 \%$. In the general conclusions, they observed that dual fuel mode was shown better than the single-fueled operation. Jothi et al. [21] used LPG and diethyl ether (DEE) in a four-stroke, direct injection and water-cooled diesel engine. The test results showed that the thermal efficiency was decreased at full load compared to diesel fuel and NOx emissions were decreased. Slight 
increases in $\mathrm{HC}$ and $\mathrm{CO}$ emissions were observed when a decrease in smoke density and PM emissions were observed. Qi et al. [22] performed their experiments at different loads and speeds on a direct injection engine with pure diesel and LPG-diesel mixture. In the test results, it was observed that the increase in the LPG ratio in the mixture led to the increase in the ignition delay, with the maximum cylinder pressure. Compared with diesel, NOx emission and smoke density were decreased. There was a slight increase in $\mathrm{CO}$ emissions at low loads. HC emissions were increased with the increase of the mass of LPG in the mixture.

In this study, the effects of LPG fumigation into the intake manifold as a secondary fuel in a diesel engine generator engine performance, combustion and exhaust emissions were experimentally investigated.

\section{METHODOLOGY}

\subsection{Experimental materials and method}

For the experiments, a generator connected to a water cooled, 4 cylinders, NWK22 model diesel engine with the power output of $18 \mathrm{~kW}$ was used. A schematic diagram of the experimental setup is given in Figure 1. A precision scale with digital indicator was used to calculate fuel consumption. The temperature was measured by means of a non-contact infrared digital thermometer.
CAPELEC CAP 3200 model diesel and gasoline emission measurement device was used for analyzing exhaust emissions in the experiments. The device is complying OIMLR99, ISO 3930 and BAR 97 standards. The commercial LPG supplied from a fuel station. Conveniently, the LPG fumigation system was mounted in the intake manifold. The FEBRIS combustion analysis software was used to analyze performance and combustion data in the experiments. Signals from a cylinder pressure sensor and crank angle encoder mechanism was used in experiment to analyze the combustion parameters. The cylinder pressure sensor records pressure data for every crank angle $\left(1^{\circ} \mathrm{CA}\right)$ and average of 100 cycles were used for drawing the curves. The data received from the signals through the FEBRIS program were simultaneously seen on the computer screen and recorded. The experimental data obtained during the experiments were observed and recorded through the FEBRIS software. By means of this it is possible to calculate many data, such as mean gas temperature, mean effective pressure, heat release rate, knock density and total heat release for each of crank angles.

Table 1 shows the physical properties and combustion characteristics of butane propane and mixture LPG fuels. The standards of the diesel fuel are shown in Table 2. The technical specifications of the engine used in the experiment are shown in Table 3.The fuel blends and their abbreviations used are shown in Table 4.

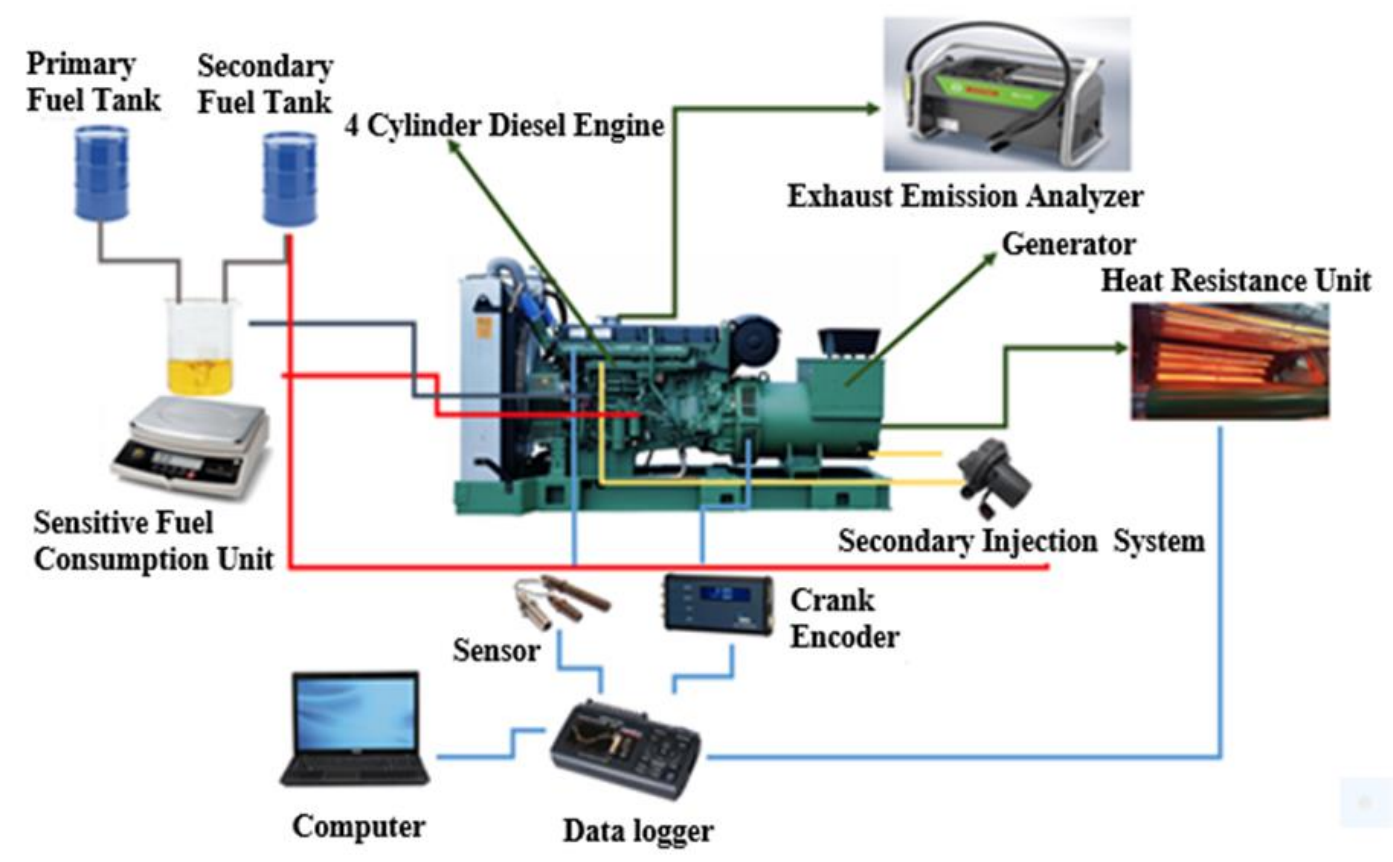

Figure 1. Experiment mechanism figure

TABLE I

TECHNICAL SPECIFICATION OF PROPANE, BUTANE AND LPG [23]

\begin{tabular}{lcccc}
\hline \hline Properties & Unit & Propane & Butane & Blends \\
\hline Closed Chemical Formula & - & $\mathrm{C}_{3} \mathrm{H}_{8}$ & $\mathrm{C}_{4} \mathrm{H}_{10}$ & $\% 30 \mathrm{C}_{3} \mathrm{H}_{8}+\% 70 \mathrm{C}_{4} \mathrm{H}_{10}$ \\
Molecular weight & $\mathrm{gr} / \mathrm{mol}$ & 44,09 & 58,12 & 53,91 \\
Liquid Form & & & & \\
Normal Boiling Point & ${ }^{\circ} \mathrm{C}$ & -42 & $-0,5$ & -13 \\
Normal Melting Point & ${ }^{\circ} \mathrm{C}$ & -190 & -138 & -154 \\
Normal Flashing Point & ${ }^{\circ} \mathrm{C}$ & -105 & -60 & -74 \\
Specific Mass (at $\left.15{ }^{\circ} \mathrm{C}\right)$ & $\mathrm{kg} / \mathrm{lt}$ & 0,508 & 0,584 & 0,560 \\
\hline \hline
\end{tabular}


TABLE II

THE STANDARDS OF THE DIESEL FUEL ACCORDING TO DINN 51601 [24]

\begin{tabular}{lcc}
\hline \multicolumn{1}{c}{ Properties } & Values & The experiment norms \\
\hline Volumetric water content & $\% 0,1$ & DIN 51777 \\
Density at $15{ }^{\circ} \mathrm{C}$ & $0.820-0,860 \mathrm{~g} / \mathrm{ml}$ & DIN 51757 \\
Distilled part up to $360{ }^{\circ} \mathrm{C}$ min. & $\% 90$ & DIN 51752 \\
Kinematic viscosity at $20^{\circ} \mathrm{C}$ & $1.8-10 \mathrm{~mm}^{2} / \mathrm{s}$ & DIN 51550 \\
Filtration & Summer $0{ }^{\circ} \mathrm{C} /$ & DIN 51770 \\
Max mass sulphur percentage & Winter $-12^{\circ} \mathrm{C}$ & DIN 51768 \\
Max mass percentage of carbon residue & $\% 1,0$ & DIN 51551 \\
Ash quantity, max ash percentage & $\% 0,02$ & DIN 51575 \\
\hline \hline
\end{tabular}

TABLE III.

TECHNICAL FEATURE OF THE ENGINE USED IN THE

\begin{tabular}{lr}
\multicolumn{2}{c}{ EXPERIMENT } \\
\hline \hline Model & \multicolumn{1}{c}{ NWK22 } \\
\hline Power output @ $1500 \mathrm{rpm}$ & $18 \mathrm{~kW}$ \\
Cooling system of the engine & Water cooled \\
The model of the engine & 4DW81-23D \\
Bore $x$ stroke $(\mathrm{mm})$ & $85 \times 100$ \\
Cylinder volume $\left(\mathrm{cm}^{3}\right)$ & 2400 \\
Number of cylinders & 4 \\
Ignition system & Direct \\
Pressurizing rate & $17: 1$ \\
\hline \hline
\end{tabular}

TABLE IV

THE FUEL BLENDS AND THEIR ABBREVIATIONS

\begin{tabular}{ccc}
\hline \hline The name of the mixture & LPG $(\%)$ & Diesel $(\%)$ \\
\hline D100 & - & 100 \\
D80 \& LPG20 & 20 & 80 \\
D70 \& LPG30 & 30 & 70 \\
D60 \& LPG40 & 40 & 60 \\
D55 \& LPG45 & 45 & 55 \\
D45 \& LPG55 & 55 & 45 \\
D35 \& LPG65 & 65 & 35 \\
\hline \hline
\end{tabular}

\subsection{Calculated Parameters}

Febris software was used to analyze combustion parameters. Cylinder gas pressure values, cylinder volume, piston acceleration, average piston speed and crankshaft position were determined through the program. Thanks to the pressure sensor, the cylinder gas pressure data is accessed. Parameters were calculated for each crank angle by means of the equations given below.

\subsubsection{Heat release rate}

According to the calculations of the ideal gas law and the first law of thermodynamics in closed systems, the heat release rate was found using the equation.

$\frac{d Q}{d \theta}=\frac{\gamma}{\gamma-1} P \frac{d V}{d \theta}+\frac{1}{\gamma-1} V \frac{d P}{d \theta}$

\subsubsection{Total heat release}

The integral of the heat release rate was prepared as the total heat release. The equation in 1 is used to calculate the accumulated heat release.

$\int d Q=\int\left(\frac{\gamma}{\gamma-1}\right) p(d V)+\int\left(\frac{1}{(\gamma-1)}\right) V(d P)$

Here is $\gamma$ a particular temperature ratio taken as $1.32, \theta$ is the crank angle, $\mathrm{P}$ is the cylinder gas pressure, and $\mathrm{V}$ is the cylinder volume. The pressure data is separated from the pressure sensor and the terms $\mathrm{V}$ and $\mathrm{dV} / \mathrm{d} \theta$ are calculated using the equation below.

$$
\begin{aligned}
& V=V c+A \cdot r\left\{1-\cos \left(\frac{\pi A}{180}\right)+\frac{1}{\lambda}\left(1-\sqrt{1-\lambda^{2} \sin ^{2}\left(\frac{\pi \theta}{180}\right)}\right)\right. \\
& \frac{d V}{d \theta}=\left(\frac{\pi A}{180}\right) \times r\left\{\sin \left(\frac{\pi \theta}{180}\right)+\frac{\lambda^{2} \sin ^{2}\left(\frac{\pi \theta}{180}\right)}{2 x \sqrt{1-\lambda^{2} \sin ^{2}\left(\frac{\pi \theta}{180}\right)}}\right\} \\
& \lambda=\frac{l}{r} \text { ve } A=\frac{\pi D^{2}}{4}
\end{aligned}
$$

Here is $r$ is the crank radius $=H / 2, l$ is the length of the rod connecting rod, D is the cylinder diameter and $\mathrm{Vc}$ is the stroke volume. The heat transfer coefficient $(\mathrm{J})$ is calculated from the cylinder wall based on the Hohenberg equation.

$\frac{d Q_{w}}{d \theta}=h A\left(T-T_{w}\right)$

The following equation gives the ratio of specific heats based on the average gas temperature.

$$
\gamma=1,338-60 \times 10^{-5} T+10^{-8} T^{2}
$$

The Hohenberg heat transfer coefficient is used in combustion analysis with the equation given below.

$$
h_{c}=C_{1} V^{-0.06} P^{0.8} T^{-0.4}\left[C_{m}+C_{2}\right]^{0.8}
$$

Here is $\mathrm{h}$ is the heat transfer coefficient, $\mathrm{V}$ instantaneous cylinder volume, $\mathrm{P}$ instantaneous cylinder pressure, $\mathrm{T}$ average gas temperature, $C_{m}$ average piston speed, and $C_{1}$ and $C_{2}$ values are experimentally found constants of $13 \times 10^{-3}$ and 1.4 respectively.

The knock intensity analysis is calculated with the following equation.

$d p(\theta)=$

$\frac{\left[86\left(p_{i-4}-p_{i+4}\right)+142\left(p_{i+3}-p_{i-3}\right)+193\left(p_{i+2}-p_{i-2}\right)+126\left(p_{i+1}-p_{i-1}\right)\right]}{1118 d \theta}$

Here is $\gamma$ is the specific temperature coefficient, Q is the apparent heat release rate calculated by the experimental equation $(\mathrm{J}) . \mathrm{P}$ is the cylinder pressure (bar), $\mathrm{V}$ is the instantaneous volume of the cylinder $\left(\mathrm{m}^{3}\right)$ and $Q_{w}$ is the temperature transfer coefficient and $\mathrm{J}$ is calculated from the cylinder wall based on the Hohenberg equation.

\subsubsection{Average gas temperature}


Average gas temperature results are taken from the regional environments of the gas temperature in the combustion chamber. The expansion stroke is considered to be polytropic and the average gas temperature is calculated by the following equation.

$T_{i}=P_{i} V_{i} \frac{T_{\text {ref }}}{P_{\text {ref }} V_{\text {ref }}}$

Here is $T_{i}$; average gas temperature, $P_{i}$ and $V_{i}$ simultaneous pressure and cylinder volume; $T_{\text {ref }}, P_{\text {ref }}$ and $V_{\text {ref }}$ are reference parameters at any point on the polytropic expansion curve.

\section{EXPERIMENTAL RESULTS AND DISCUSSION}

Figure 2 shows the variation of the cylinder pressure values of the test fuels with respect to the crank angle of at $1500 \mathrm{rpm}$ at $10.8 \mathrm{~kW}$ load. The highest cylinder pressure was observed for D35LPG65 fuel. The lowest cylinder pressure was observed for D100, pure diesel fuel. Generally, as the rate of LPG used increases, the pressure curve changes almost proportionally. This is considered to be due to the increase in ignition delay. At the same time, the amount of fuel burned during the uncontrolled combustion period also increased, and resulted to an increased peak pressure. As a result, the formation of the pressure curve for the D35LPG65 fuel is quite different from the other fuels and it can be said that this curve constitutes a diesel knock limit in the use of LPG. The reasons for this situation, which are accompanied by an increase in the LPG ratio; it that the LPG is a gasolinelike fuel with low cetane number, high auto ignition temperature and high flame speed after burning.

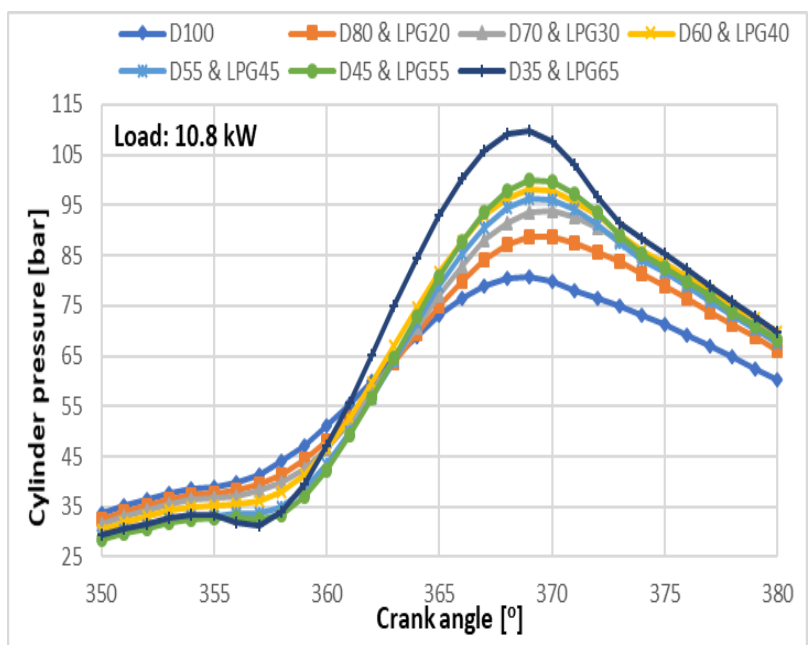

Figure 2. Cylinder pressure change with crank angle for test fuels

As can be seen in Figure 3, the highest heat release rate was observed for the D35LPG65 fuel. The lowest heat release rate was observed for pure diesel fuel D100. The formation of the heat release curve for D35LPG65 fuel is considerably different compared to the other fuels. This situation is due to the characteristics of LPG as mentioned above. As it can be seen in Figure 3, the combustion process of the D35LPG65 fuel is delayed, and after the combustion starts, there is an uncontrolled and rapid combustion that lead to excessive heat release in the combustion chamber. This can be attributed to the prolonged ignition delay period and the accumulated amount of fuel and flame speed, which is high after combustion starts.

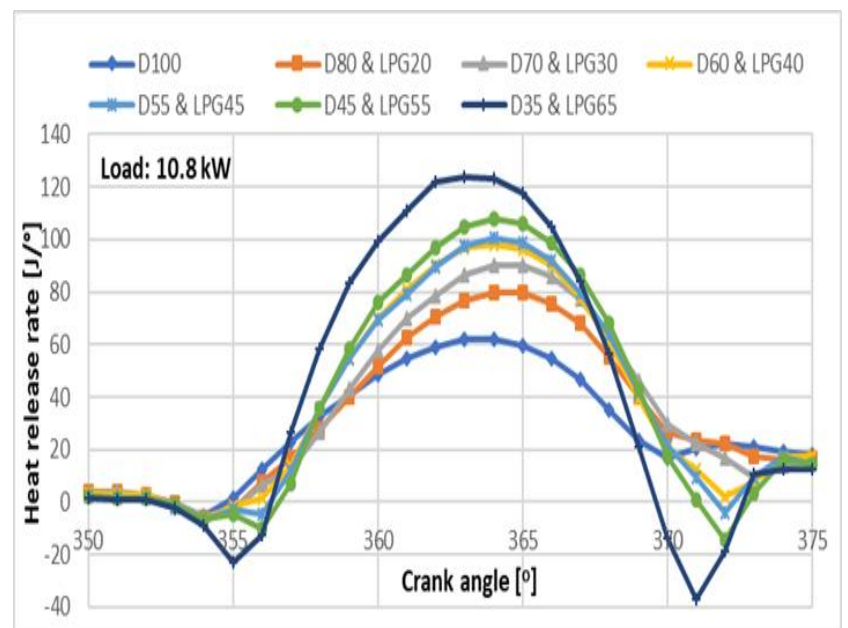

Figure 3. Change in rate of heat release rate for test fuels

As can be seen in Figure 4, the highest total heat release was observed for D35LPG65 fuel. The lowest total heat release was observed for pure diesel fuel D100. Total heat release curves differed from the diesel fuel with increased LPG amount. The total heat release curve due to the use of D35LPG65 fuel is quite different and the reasons of these are due to the characteristics of LPG as mentioned earlier.

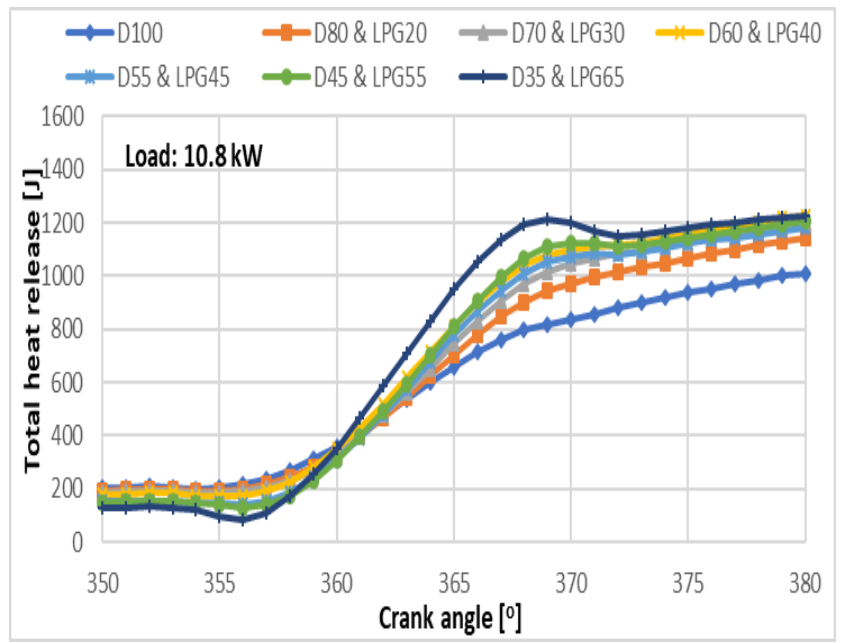

Figure 4. Crank-related change in total heat release rate

As can be seen in Figure 5, the highest average gas temperature was observed for D35LPG65 fuel. The lowest average gas temperature was observed for pure diesel fuel D100. The use of D35LPG65 fuel resulted in very high cylinder temperatures. All of the combustion results mean that $50 \%$ of LPG usage can be allowed. But above the mentioned reasons that the combustion can be classified as a diesel knock. The increase in exceeding heat transfer zones created by the turbulent flame zones in the combustion chamber during the diesel knock causes an increase in the overall hot combustion chamber. For this reason, the average cylinder gas temperatures are maximized in the case of D35LPG65. 


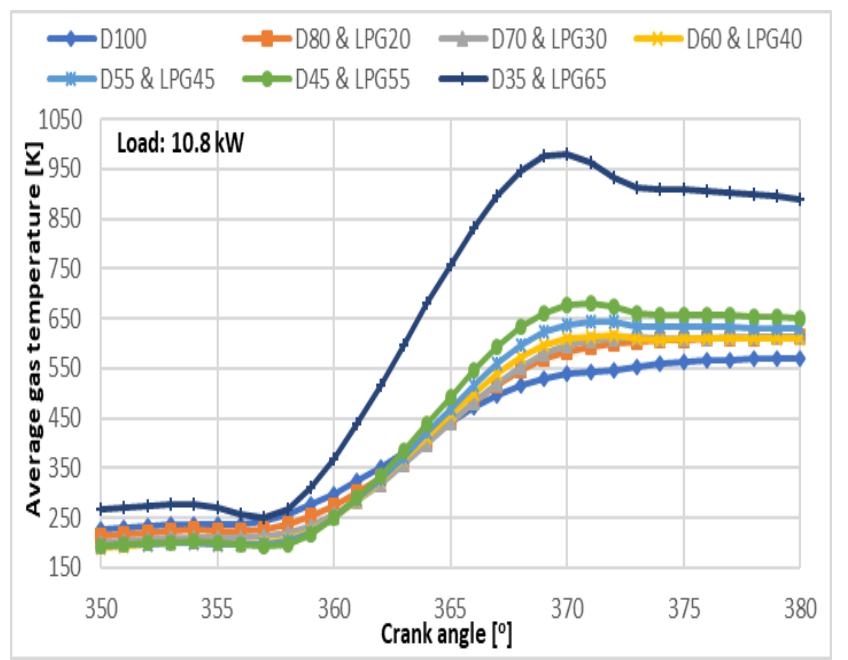

Figure 5. Crank-related change in average gas temperature

In Figure 6, burning of D35LPG65 fuel which also can be supported by the figures given above is classified as the knock as mentioned earlier. In the case of the D35LPG65, the knock intensity values were maximized. In general, the increase in the LPG ratio has increased the tendency to knock.

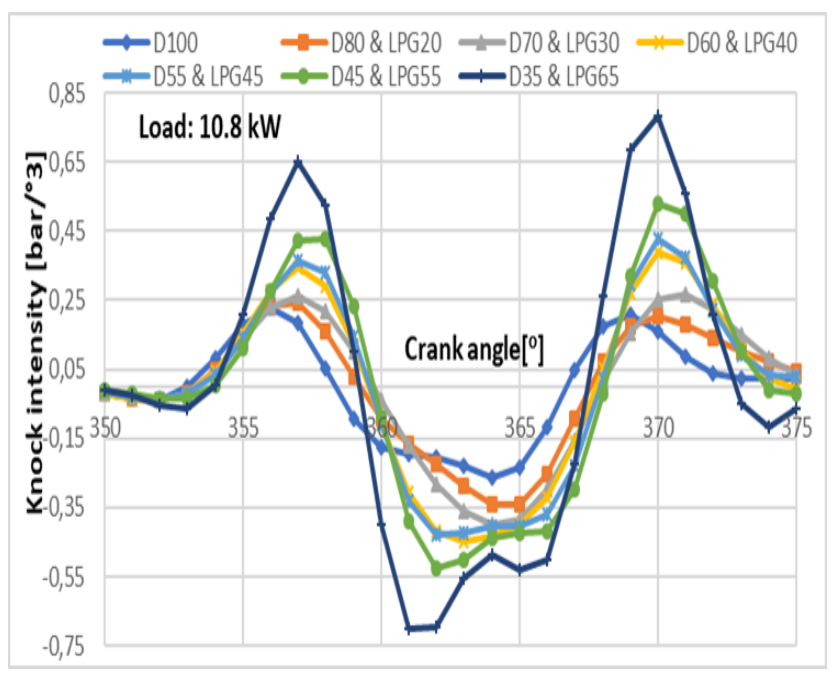

Figure 6. The change of the knock intensity due to cranking

Figure 7 graphically shows the amount of specific fuel consumption for each fuel at full load. When the figure was examined, the lowest specific fuel consumption was observed for pure diesel (D100). This ratio was increased significantly when using $45 \%$ and $55 \%$ LPG. The highest specific fuel consumption was observed for the D35LPG65. In fact, the unsteadiness in the engine operation was increased when the LPG ratio was increased. Therefore, the specific fuel consumption was reduced due to the cyclic changes and reduced engine speed along with knocking. Reduction in engine speed resulted in reduced specific fuel consumption in the case of D35LPG65. This was reduced engine power as well. As a result, specific fuel consumption was increased. However, the use of LPG up to approximately $50 \%$ did not adversely affect the engine's excessive specific fuel consumption and unsteady engine operation.

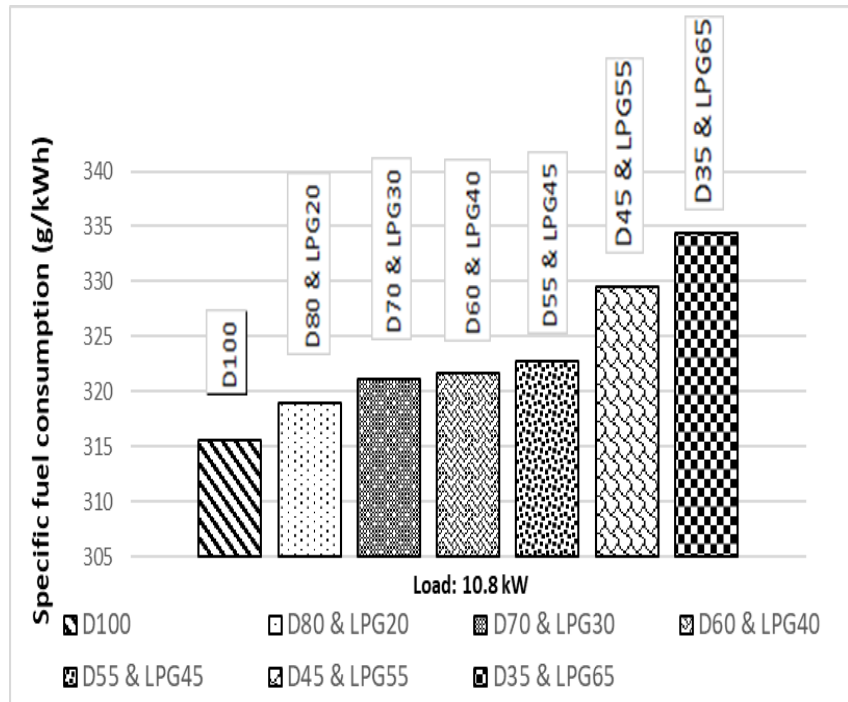

Figure 7. Changes in specific fuel consumption with LPG ratio

Figure 8 represents thermal efficiency values that symbolize the ratio of heat energy generated by combustion of the fuel to the engine converting rate of this energy into useful work. According to the obtained graphical results, the highest thermal efficiency was observed for pure diesel (D100). In general, thermal efficiency drops due to the use of LPG. The lowest thermal efficiency was observed for the D35LPG65 operating mode. Since the use of LPG is limited by knocking, it is not possible to calculate and interpret the thermal efficiency for D35LPG65.

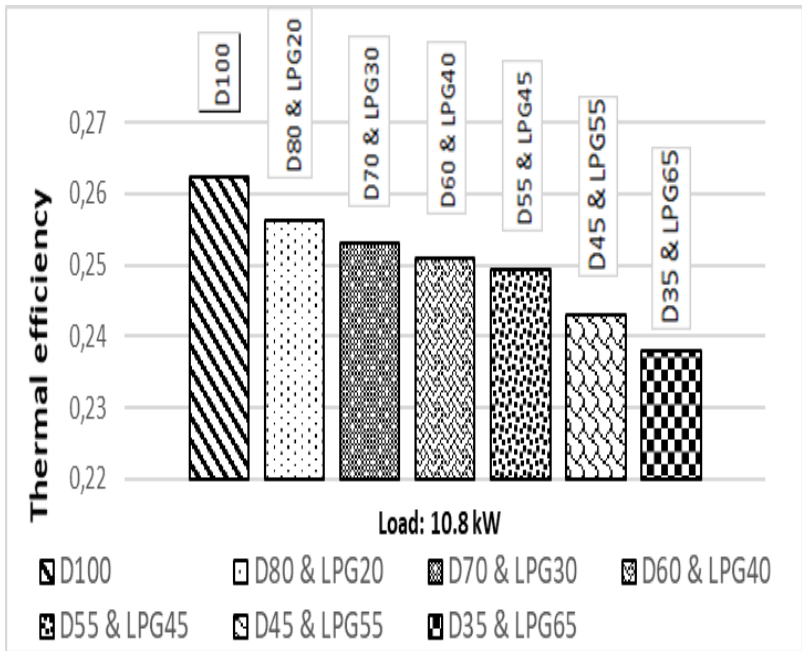

Figure 8. Variation of thermal efficiency values according to LPG ratio

Figure 9 shows the temperature of the gases passing through the exhaust manifold. The lowest exhaust gas temperature according to the graphs was observed for pure diesel fuel D100. Besides, as the LPG addition was increased, there was a steady increase in the overall exhaust gas temperature. The highest exhaust gas temperature was observed for D35LPG65 fuel.

The exhaust gas temperature of the dual fuel operation is higher than the single fuel operation. This is probably due to the fact that the end-of-combustion temperatures in the cylinder during the dual-fuel operation are higher than the end-of- combustion temperatures for single-fuel operation. 


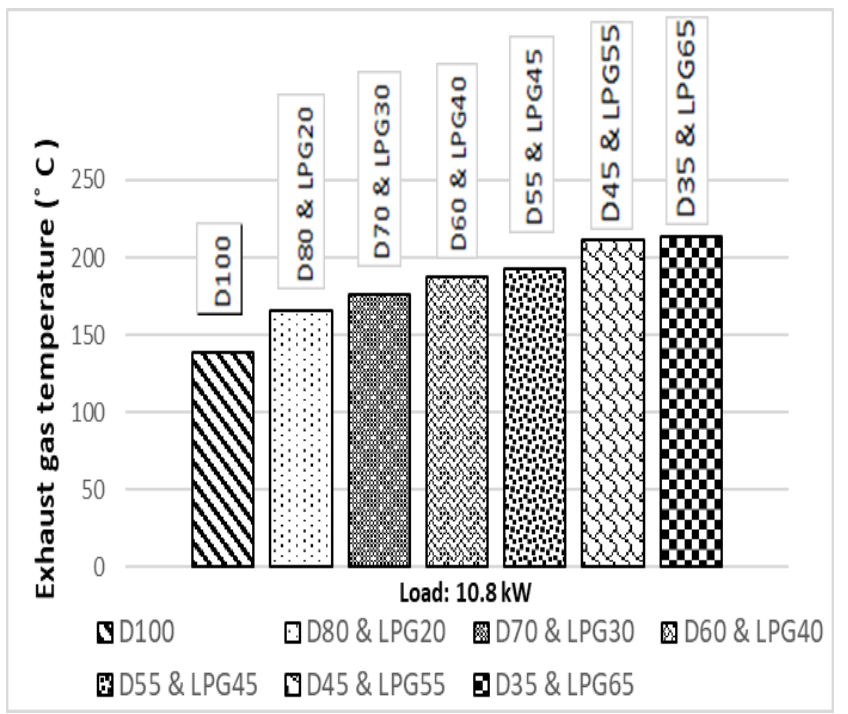

Figure 9. Variation of exhaust manifold temperature according to LPG ratio

The exhaust gas temperature is also increasing with the increase of the temperature inside the cylinder. The increase in exhaust gas temperature is indirectly related to nitrogen oxide emissions [16].

Figure 10 shows the mas fuel consumption for the test fuels. The highest mass fuel consumption according to the graphs was observed in the D35LPG65 operation. The lowest mass fuel consumption was observed for pure diesel fuel D100. Namely, fuel consumption was increased when the LPG ratio was increased. However, with the use of excessive LPG, the mass fuel consumption was reduced due to the change in speed caused by the unsteady operation of the engine together with the formation of the engine knock. The decline in engine speed resulted in a reduction in mass fuel consumption after the D35LPG65. Actually, it can be said that mass fuel consumption was also increased. However, the use of LPG until approximately $50 \%$ did not have a negative effect on engine operation.

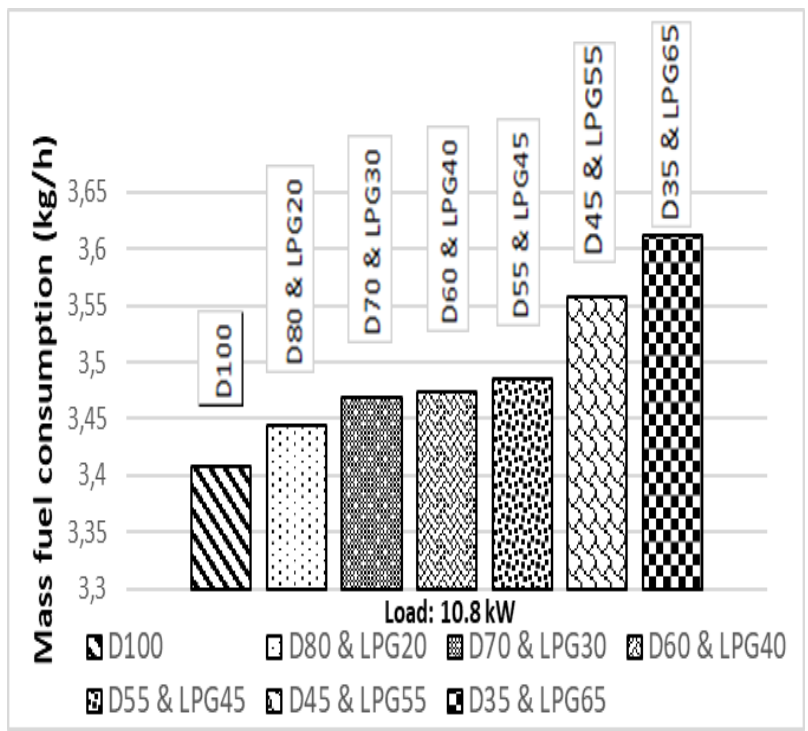

Figure 10. Change of mass fuel consumption by LPG ratio

Figure 11 shows the changes in $\mathrm{CO}$ emissions of fuels. The lowest amount of $\mathrm{CO}$ emissions was observed for pure diesel fuel D100. As the amount of LPG increased, the in-cylinder charge was enriched and increased the CO emissions.

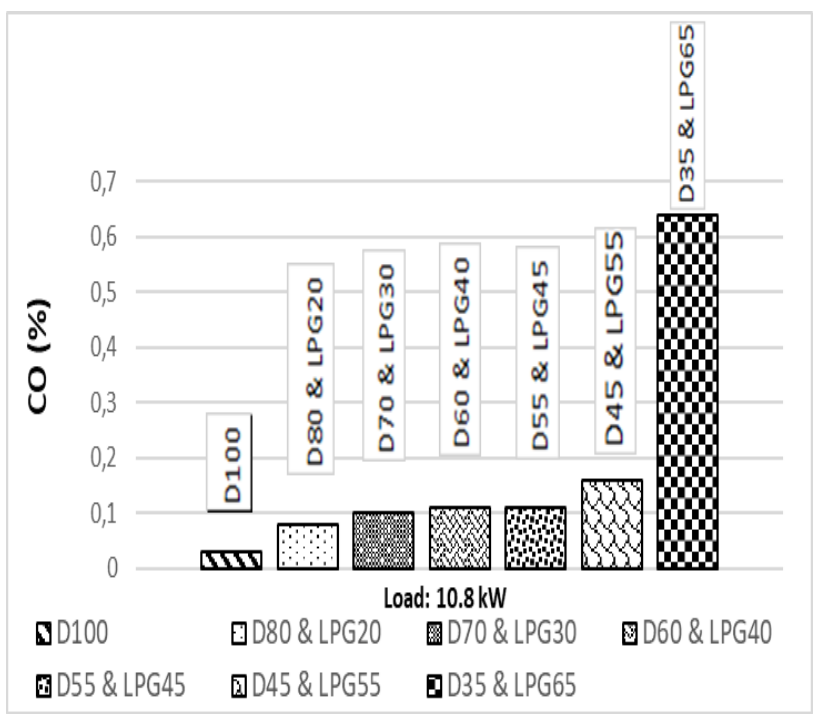

Figure 11. Change of $\mathrm{CO}$ emission according to LPG ratio

The main reason for the presence of $\mathrm{CO}$ in combustion products is the inadequate oxygen amount. Considering the combustion chamber as, oxygen may generally be inadequate, but if the mixture is not completely homogeneous, the oxygen may also be inadequate at a certain place in the combustion chamber. As a main reason, $\mathrm{CO}$ formation varies as a strong function of the air excess factor. The fact that the distribution of fuel in the combustion chamber is not the same prevents the combustion to occur in a uniform condition. For this reason, there will be an increase in the incomplete reaction and incomplete combustion of hydrocarbons. Namely, the CO formation is due to reasons such as heterogeneous distribution of air in the combustion chamber, insufficient oxygen and low reaction temperature [25].

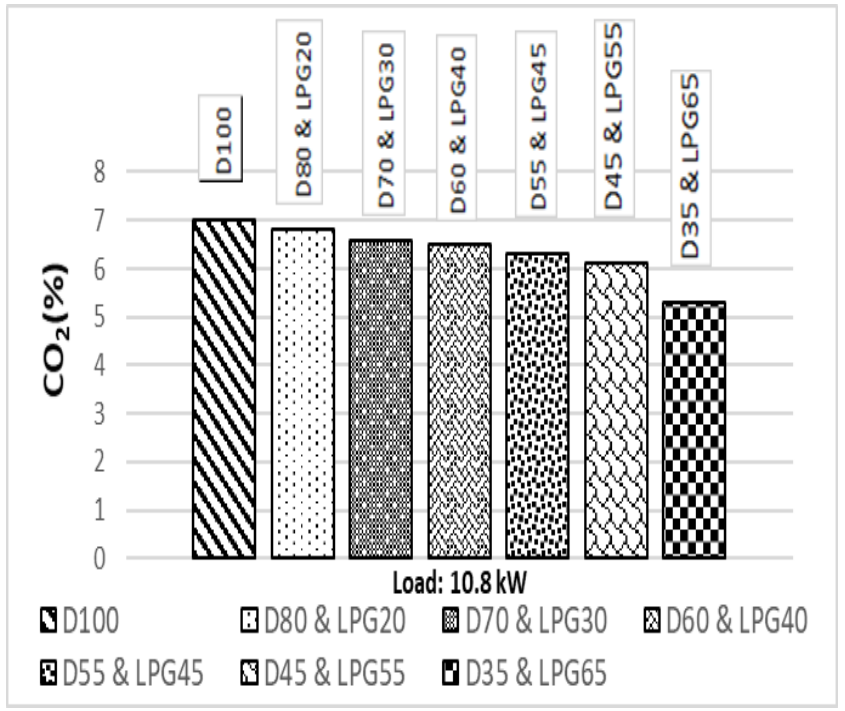

Figure 12. Change of $\mathrm{CO}_{2}$ emission according to LPG ratio

The changes in $\mathrm{CO}_{2}$ emissions of the fuels used in the experiment are shown in Figure 12. When the graphs are analyzed, it is observed that the use of LPG-added diesel fuel according to D100, which is the $\mathrm{CO}_{2}$ emission change pure diesel fuel, shows a steady decrease to the $40 \%$ LPG ratio 
and a significant decrease in the $\mathrm{CO}_{2}$ level in the mixture with more than $40 \%$ LPG. The lowest $\mathrm{CO}_{2}$ emission by graph was observed for D35LPG65 fuel. In the cases of D45LPG55 and D35LPG65, as the amount of fuel entering increased, a rich mixture formed and $\mathrm{CO}$ emission increased, thus leading to a decrease in $\mathrm{CO}_{2}$ emissions.

In flame fronts, reactions reach equilibrium when high temperatures are reached. However, good mixing of the blend and turbulent burning tend to increase the $\mathrm{CO}_{2}$ ratios as the $\mathrm{CO}$ in the flame zone is converted to $\mathrm{CO}_{2}$. The amount of $\mathrm{CO}_{2}$ was lower in all LPG percentages than in the pure diesel fuel D100 fuel. This is thought to be due to the fact that the combustion temperature of LPG usage is lower that result in in-complete combustion. Another reason may be the rich fuel-air ratio of the burning charge with the use of LPG [26].

In Figure 13, the lowest $\mathrm{HC}$ release was for pure diesel (D100). The highest HC emissions were observed for D35LPG65 fuel.

With the addition of LPG, there was an increase in $\mathrm{HC}$ emissions in general. Increasing the amount of LPG reduces the amount of diesel fuel in dual-fuel experiments. The reduction in diesel fuel also causes a decrease in the heat energy that will increase the LPG usage. The increase in the amount of HC emissions in the LPG usage may be caused incomplete combustion due to the fuel rich zones in the combustion chamber. It is thought that the rapid increase of $\mathrm{HC}$ amount is due to the beginning of irregular burning [16]. In addition, with the use of LPG, HC emissions are seen to increase considerably. This can be interpreted as the deterioration of the air fuel ratio and the lack of oxygen in the combustion chamber.

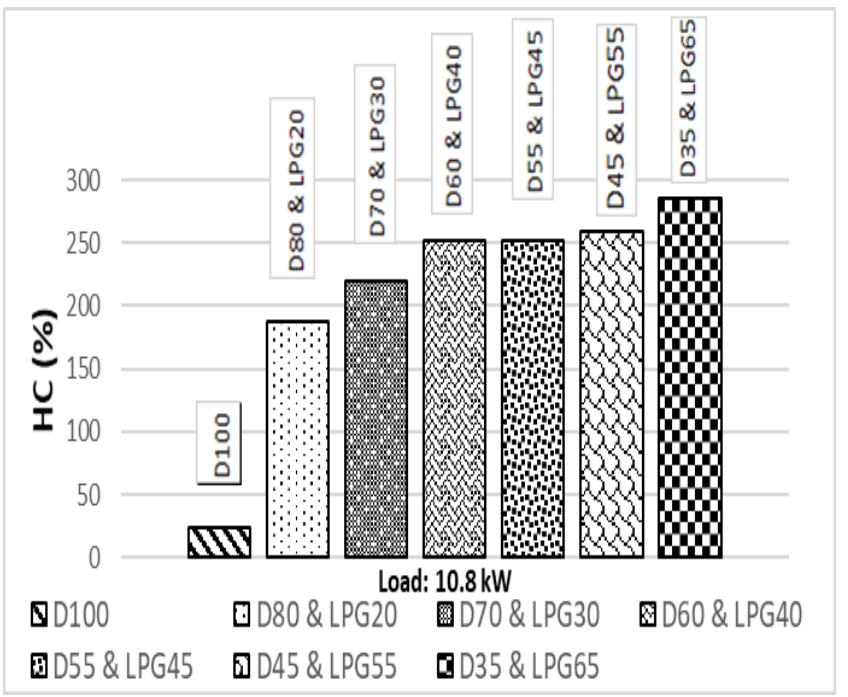

Figure 13. Change of $\mathrm{HC}$ emission according to LPG ratio

As seen in Figure 14, the $\mathrm{O}_{2}$ measurements of pure diesel fuel (D100) and dual fuel D80LPG20 and D70LPG30 were almost similar. D45LPG55 decrease was about 6\%, while there was a decrease of about 19\%.in D35LPG65 usage.

A reduction in the amount of air in the cylinder reduces the amount of oxygen released from the exhaust. Because LPG-homogeneous mixture with air causes more air around the fuel particles during the combustion, it also causes decrease of oxygen amount. In addition, in dual fuel experiments, the amount of air in the cylinder is as low as the amount of LPG taken into the cylinder, resulting in a low amount of oxygen due to the relatively rich fuel-air mixture [26].

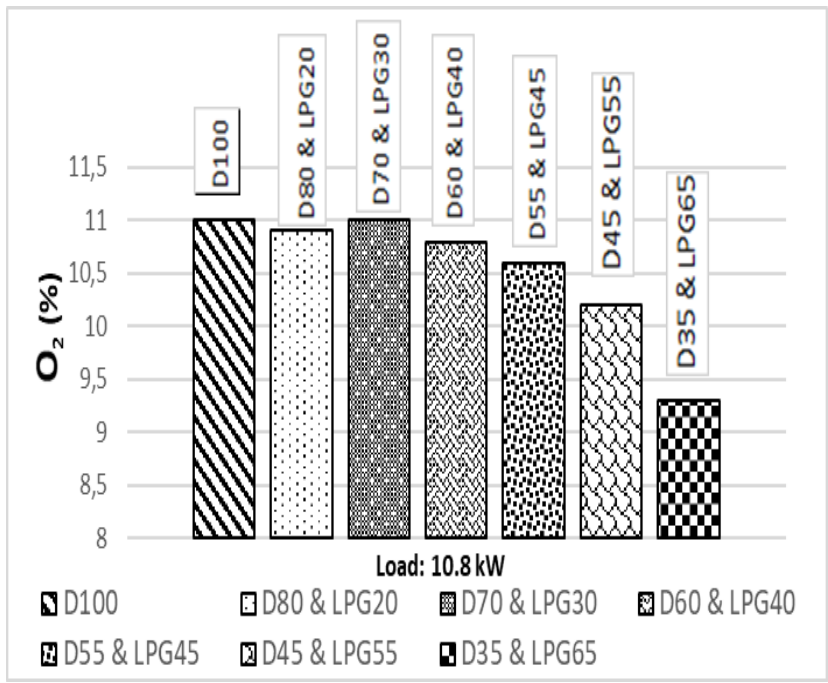

Figure 14. Change of $\mathrm{O}_{2}$ emission according to LPG ratio

As shown in Figure 15, initially the NOx values of pure diesel fuel (D100) and LPG RCCI modes were similar. The highest NOx value was observed for D35LPG65 fuel. With increasing LPG ratio, there was usually a decrease in NOx emission values. However, there were increases in NOx emissions for LPG55 and LPG65 modes. This may be attributed to the increased uncontrolled combustion phase due to the increased combustion chamber temperatures and knock formation. In general, it is observed in the graph that there was a decrease in NOx emissions as the LPG content increases.

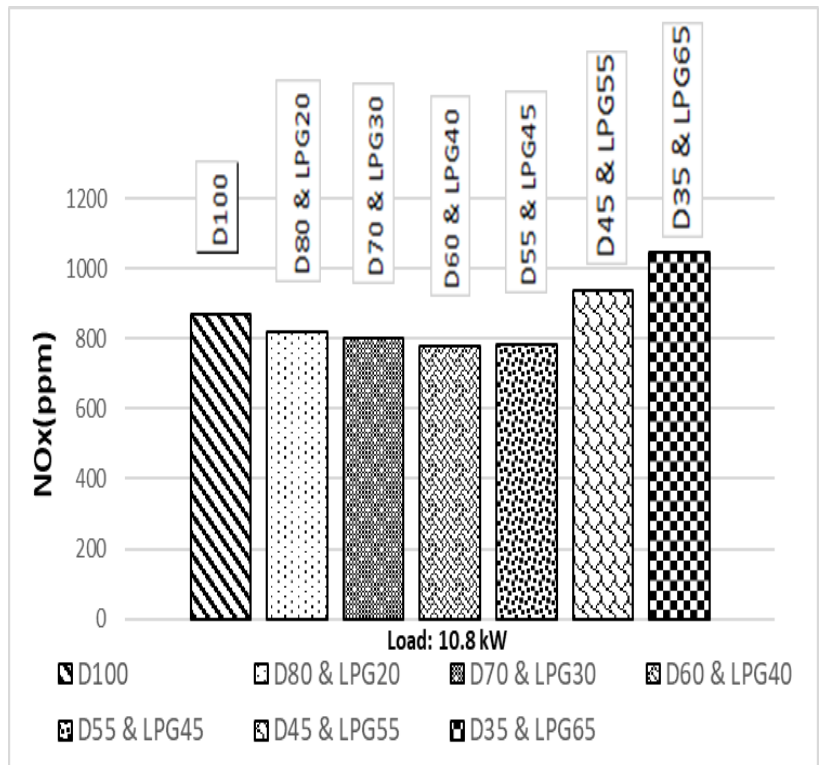

Figure 15. Change of NOx emission according to LPG ratio

The density of the smoke values according to the LPG ratio is shown in Figure 16. As can be seen, the increase in the pilot LPG ratio reduced the density of exhaust gases, so the amount of smoke. However, after a certain LPG rate, the deterioration of the combustion caused the smoke density 
values to increase again. The ideal smoke density values were observed in the D55LPG45 mode.

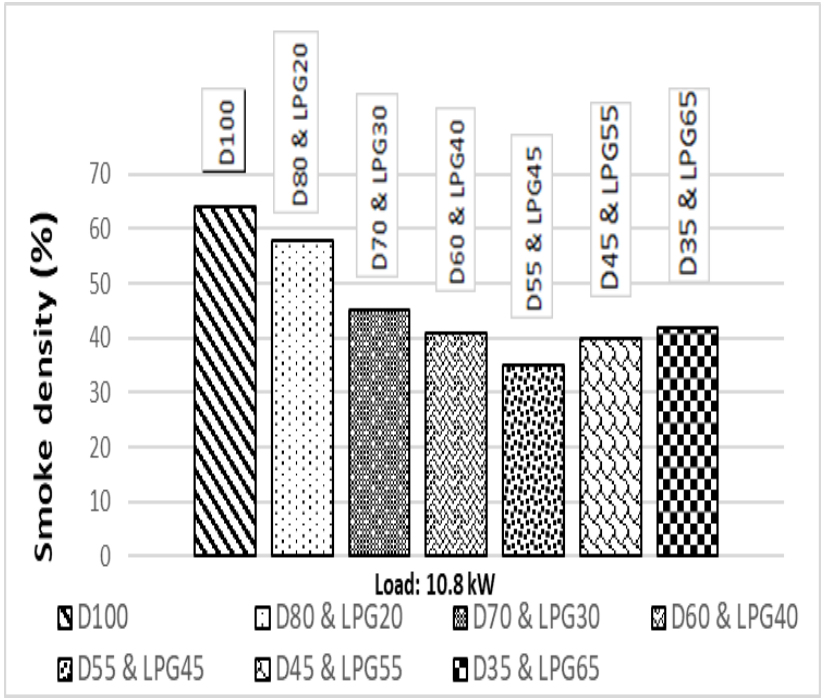

Figure 16. Change of smoke density values according to LPG ratio

\section{CONCLUSIONS}

In this study, engine performance, combustion and emissions a diesel engine used for driving an electrical generator was investigated with LPG fumigation into the manifold of the engine as secondary fuel. Briefly the following results were obtained.

According to the results obtained from the experiments; an increase in cylinder pressure was observed with increase in the LPG ratio in general and it was seen as the tendency of knocking when the LPG ratio was excessively high. Exhaust gas temperatures were deteriorated up to $54 \%$ with amount of LPG. It can also be said that specific fuel consumption and mass fuel consumption were also increased up to $\% 12$ while the mixture of high amount LPG with diesel is decreased $3 \%$. Over 55\% LPG fumigation resulted in quite high flame velocity and propagation which eventually resulted in the accelerated pressure increase for per crank angle. This condition may be accepted as the starting of the knock. Therefore only certain low amounts of LPG usage as secondary nonreactive fuel in diesel engine were found to be possible.

When examining emission test results; up to $2033 \%$ increase was observed for CO emission and up to $1088 \%$ of $\mathrm{HC}$ emission was increased as well. $\mathrm{CO}$ and $\mathrm{HC}$ emission values were increased with the addition of LPG. With increasing LPG, there was a decrease in the NOx emission values. That decrease was up to $16 \%$. As can be seen, the increase in the pilot LPG ratio reduced the density of exhaust gases, so the amount of smoke. However, after a certain LPG rate, the deterioration of the combustion caused the smoke density values to increase again. The ideal smoke density values were observed in the D55LPG45 mode.

In general, experiments have shown that the use of LPG as a secondary fuel in diesel engines makes it possible to use LPG at certain rates instead of diesel fuel in terms of similar combustion, performance and emission values.
Usage of LPG in engine improve exhaust emissions better than existing fuels and in order to increase efficiency along improved emissions, some additives for LPG can be tested. Additionally, the effect of LPG usage on engine parts should be evaluated for a long term. In the future study, cost analysis and current resources of LPG can be made to demonstrate its position in market. Lastly, the impact of advanced injection technologies such as pilot injection is needed to demonstrate and compare with this paper.

\section{REFERENCES}

[1] Ögüt, H., and R. Kus. (1999). Alternative fuel usage in motor vehicles, II. Transportation and traffic congress report book, TMMOB, Mechanical Engineering Publishing. 149-162.

[2] Ünal, F. (2021). Energy and exergy analysis of an industrial corn dryer operated by two different fuels. International Journal of Exergy, 34(4), 475-491.

[3] Sertcelik, N. Effects of using LPG in dual fuel diesel engine on performance and emission, Master's thesis, Gazi university, Ankara, TR, 2010.

[4] Gümüş, M. (2009). The effect of LPG using ratio on performance and emission characteristics in a spark ignition engine with dual fuel injection, The Journal Of The Engineering And Architecture Faculty Of Gazi University, Vol. 24, No. 2, 265-273.

[5] S. Kannan, S. Mahalingam, S. Srinath, M. Sivasankaran, and S. Kannan, "An experimental study in HCCI combustion of LPG in diesel engine," Mater. Today Proc., vol. 37, pp. 3625-3629, 2021, doi: https://doi.org/10.1016/j.matpr.2020.09.774.

[6] E. Anye Ngang and C. V. Ngayihi Abbe, "Experimental and numerical analysis of the performance of a diesel engine retrofitted to use LPG as secondary fuel," Appl. Therm. Eng., vol. 136, pp. 462-474, 2018,

doi:https://doi.org/10.1016/j.applthermaleng.2018.03.022.

[7] T. Vinoth, P. Vasanthakumar, J. Krishnaraj, S. K. ArunSankar, J. Hariharan, and M.Palanisamy, "Experimental Investigation on LPG + Diesel Fuelled Engine with DEE Ignition Improver," Mater. Today Proc., vol. 4, no. 8, pp. 9126-9132, 2017, doi: https://doi.org/10.1016/j.matpr.2017.07.268.

[8] C. Guan, C. S. Cheung, Z. Ning, P. K. Wong, and Z. Huang, "Comparison on the effect of using diesel fuel and waste cooking oil biodiesel as pilot fuels on the combustion, performance and emissions of a LPG-fumigated compression-ignition engine," Appl. Therm. Eng., vol. 125, pp. 1260-1271, 2017,doi:https://doi.org/10.1016/j.applthermaleng.2017.07.17.

[9] A. Rimkus, M. Melaika, and J. Matijošius, "Efficient and Ecological Indicators of CI Engine Fuelled with Different Diesel and LPG Mixtures," Procedia Eng., vol. 187, pp. 504-512, 2017 , doi: https://doi.org/10.1016/j.proeng.2017.04.407.

[10] A. IRGIN, M. AYDIN, and M. B. ÇELIK, "Tek Silindirli Bir Dizel Jeneratörde Dizel/LPG Çift Yakıtının Performans ve Emisyonlara Etkisi," 2017.

[11] A. Nugroho, N. Sinaga, and I. Haryanto, "Performance of a compression ignition engine four strokes four cylinders on dual fuel (diesel-LPG)," in AIP Conference Proceedings, 2018, vol. 2014, no. 1, p. 20166.

[12] F. Ünal, H. Bulut, and A. KAHRAMAN, "Lpg Yakıtlı Endüstriyel Yatay Tip Misır Kurutma Tesisinin Enerji ve Maliyet Analizi," DÜMF Mühendislik Derg., vol. 11, pp. 161170, Mar. 2020, doi: 10.24012/dumf.452540.

[13] S. Aliustaoğlu and V. Ayhan, "Direk Enjeksiyonlu Bir Dizel Motorda Lpg-Dizel Çift Yakit Karişiminin Performans Ve İs Emisyonlarina Etkileri," İleri Teknol. Bilim. Derg., vol. 8, no. 2, pp. 109-116. 2019.

[14] S. Sendilvelan and C. Sundarraj, "Performance and emission study on a dual fuel engine with modified gas inlet," Int. J. Heat Technol., vol. 34, no. 3, pp. 545-550, 2016.

[15] Aktaş, A., and O. Doğan. (2010). Effect of LPG percentage to performance and exhaust emissions in a dual fuel engine, The Journal Of The Engineering And Architecture Faculty Of Gazi University, Vol. 25, No. 1, 171-178.

[16] Yiğit, A.The usage of LPG in a diesel engine and the observation of the effects of different kinds of pilot diesel fuel on the 
performance of the engine and emission, Master's thesis, Karabuk university, Karabuk, Tr, 2008.

[17] Saleh, H.E. 2008. Effect of variation in LPG composition on emissions and performance in dual fuel diesel engine, Fuel, Vol.87,No.(13-14),3031-3039.doi:10.1016/j.fuel.2008.04.007.

[18] Aydin, F., and M. Acaroğlu, (2009). Investigation of vehicle performance and exhaust in sequential gas phase LPG injection system, 10. Combustion Symposium.

[19] Alla, G.A., H. Soliman, and O. Badr, M.A. Rabbo, (2000). Effect of pilot fuel quantity on the performance of a dual fuel engine, Energy Conversion and Management, Vol. 41, No. 6, 559-572. doi:10.1016/S0196-8904(99)00124-7.

[20] Çarman, K., S. Salman, and M. Ciniviz. (2001). Effects on performance and emissions using diesel fuel and LPG on the diesel engines, Technical Online Journal Faculty Of Selçuk University, Vol. 2, No. 1, Issn, 1302-6178

[21] Jothi, N.M., G. Nagarajan, and S. Renganarayanan. (2007) Experimental studies on homogeneous charge $\mathrm{CI}$ engine fueled with LPG using DEE as an ignition enhancer, Renewable Energy,Vol.32,No.9,1581-1593. doi:/10.1016/j.renene.2006.08.007.

[22] Qi, D., Y. Bian, Z. Ma, C. Zhang, and S. Liu. (2007). Combustion and exhaust emission characteristics of a compression ignition engine using liquefied petroleum gasDiesel blended fuel, Energy Conversion and Management, Vol. 48, No. 2, 500-509. doi:/10.1016/j.enconman.2006.06.013.

[23] LPG System. Accessed November 20,2017. http://www.ipragaz.co/brosurler/dokmegaz/araci-firma segmantasyon-katologu.pdf

[24] Borat, O., M.A. Balcı, and A. Sürmen. 1994. Internal Combustion Engines, G.U. Technical Education Foundation Publications-2.

[25] Koca, D. Ö.The experimental investigation of the diesel and LPG fuels together diesel engine, Master's thesis, Yildiz technical university, İstanbul, TR, 2013.

[26] Ciniviz, M. Effect on performance and emission of using diesel fuel and LPG on diesel engines, Master's thesis, Selcuk university institute of science and technology, Konya, TR, 2001.

\section{BIOGRAPHIES}

Ahmet Aydın graduated from Department of Mechanical Engineering at University of Batman at 2014. He gained her MSc. degree at the same university at 2017. His main research fields are energy and internal combustion engines.

Hüseyin Aydın graduated from Department of Mechanical Education at University of Dicle at 2004. He gained his Ph.D. degree at the Firat university at 2011. He is working as Professor at University of Batman, department of Mechanical Engineering since 2011. His main research fields are combustion, automotive and energy. 